\title{
Experimental development of low flow rate pressure feed system and design of installation for analysis of work process in hydrogen synthesis power systems on powder aluminium
}

\author{
Dmitry Alexeevich Yagodnikov, Yuri Nikolaevich Vlasov, Nikolai Ivanovich Bykov, \\ Ivan Anatoljevich Desyatnichenko, Olesya Andreevna Vorozheeva
}

Moscow State Technical University named after N. E. Bauman, Moscow, Russia

\section{Email address:}

daj@bmstu.ru (D. A. Yagodnikov), unvlasov@yandex.ru (Yu. N. Vlasov), ollikahnstex@rambler.ru (N. I. Bykov), ivan1234590@gmail.com (I. A. Desyatnichenko), oa-vorozheeva@mail.ru (O. A. Vorozheeva)

To cite this article:

Dmitry Alexeevich Yagodnikov, Yuri Nikolaevich Vlasov, Nikolai Ivanovich Bykov, Ivan Anatoljevich Desyatnichenko, Olesya Andreevna Vorozheeva. Experimental Development of Low Flow Rate Pressure Feed System and Design of Installation for Analysis of Work Process in Hydrogen Synthesis Power Systems on Powder Aluminium. Science Journal of Energy Engineering. Vol. 1, No. 2, 2013, pp. 5-12. doi: 10.11648/j.sjee.20130102.11

\begin{abstract}
Installation is designed for experimental development of pressure feed system of low consumption (1-10 g/s) of powder metal (including aluminum powder brands ASD, PAP, PAD) to combustion zone of combustion chamber. It allows choosing optimal lift gas for powder metal fluidization, calibrating powder gas suspension flow measurement fitting and minimizing lift gas expenditure in powder metal flow using drum-type gas counter GSB-400.
\end{abstract}

Keywords: Oxidation of Aluminum, Powder Metal, Fluidization, Processes in the Combustion Chamber, the Synthesis of Hydrogen, Supply System, Thermodynamic Calculations

\section{Introduction}

Over the last few decades area of practical application of powder metals (PM), which enable enhancement of energetic and operational characteristics of propulsion packs and high level procedure specifications development as well, is constantly developing.

Large-scale implementation of recent developments of military industrial complex into non-military industries appears to be logically necessary for support of priorities achieved by our country. In recent years economically feasible interest towards efficient use of engineering and technological experience gathered during special propulsion packs development in the process of development of technical devices has formed.

Development of creation principles of tarnishing power installations for preparation of oxides with minimal impurity percentage, engineering of hydrogen synthesis power systems, application of new fuels including use of powder metals are the most distinctive and permanent trends of power engineering development..

\section{Installation}

One of directions of technology development in demand at present is creation of high-efficiency installations on basis of aluminum oxidizing reaction [3] in air or in water vapor for enhancement of work process characteristics both in propulsion packs and in hydrogen synthesis power systems as hydrogen is considered to be fuel of the future since its conversion to heat and electric energy in thermal engines allows production of higher temperatures of vapor-gas mixtures than in the process of natural gas firing which essentially increases energy generation efficiency. Besides, hydrogen use allows decreasing essentially carbon oxide and dioxide emissions to the atmosphere.

For examination of current proposals of efficient aluminum use in process of its interaction with water or air, development of experimental test procedures it's necessary to create experimental plant allowing research on work process characteristics and optimization of its certain stages and construction components. 


\subsection{Pneumatic-Hydraulic Installation}

Pneumatic-hydraulic circuit of multi-purpose bench allowing analysis of processes in propulsion packs and features hydrogen synthesis process is shown on Fig. 1.

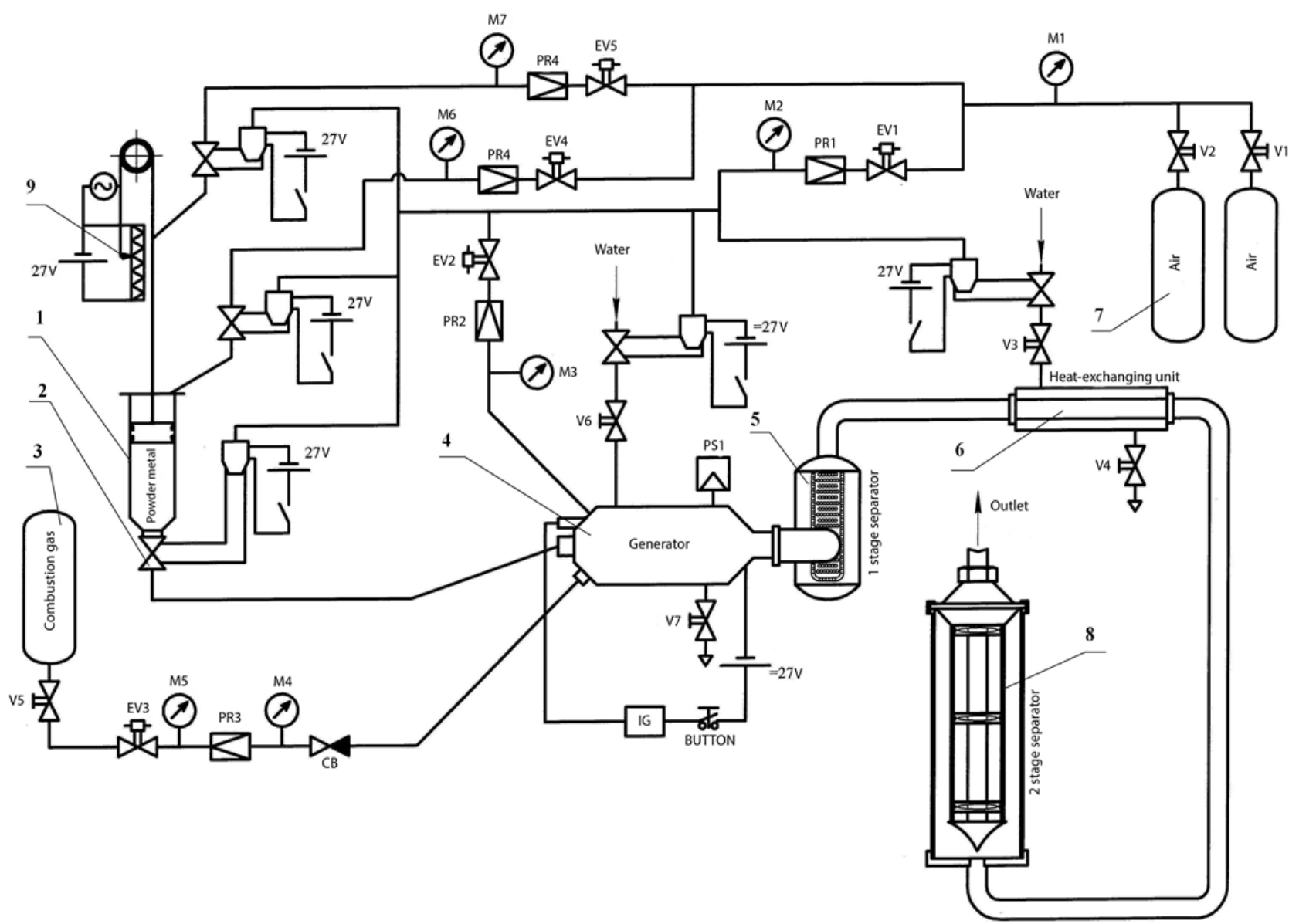

Figure 1. Pneumatic-hydraulic installation for combustion chamber work process characteristics analysis. 1 - powder metal tank; 2 - shutoff valve; 3 capacity with gas for "following torch"; 4 - generator combustion chamber; 5 - 1 stage separator; 6 - heat-exchanging unit; 7 -air pressure accumulator; $8-2$ stage separator; 9 - powder metal expenditure determination device

Multi-purpose bench allows to optimize both regimes of powder supply wherefore the bench is equipped with powder and gas expenditure measuring system on a real time basis and powder metal 9 ignition and combustion regimes both with air (oxygen) and with water. Pneumatic-hydraulic circuit allows to change components correlation and their expenditure in gas-generator.

The installment consists of powder feeder 1 and gas generator 4 with combustion chamber that is designed for organization of powder metal combustion process with air, supplied from balloons 7 or water, supplied through shutoff valve and BH6 isolator from feed line. In process of optimization of work process of powder metal combustion with water high temperature "following torch" is planned if needed. It appears to be combustion products of air and combustible gas (propane) from balloons 3. Products available from the reaction in the combustion chamber flow to stage 1 cyclone separator 5 where division of particles of condensed phase takes place. By means of two stages cleaning separation of gas and condensate components of postcombustion flow is provided. Since on the stage 2 of separation capron filters are used combustion products cooling in heat-exchanging unit installed after the stage 1 of separation is provided.

After separated reaction products cooling in heat-exchanging unit 6 they flow to 2nd stage separator 8 where by means of filters dispersion of ultradispersed fractions of condensed phase and hydrogen that is utilized in outlet is made.

\subsection{Research on Powder Supply Regimes on Cold Gas}

Through studies of powder supply regimes on cold gas heat-exchanging unit is not used and instead of it gathering facility of powder and gas total volume flow specification on a real time basis is installed. Powder and gas is gathered to a special capacity equipped with transparent window that allows photo and video shooting of stream flowing out of the injector. Capacity for powder and gas gathering (continuous pipe in diameter of $100 \mathrm{~mm}$ and in length of $700 \mathrm{~mm}$ ) is equipped with system of cleaning and carrier gas expenditure measuring including multilayer powder filter and gas flow counter of volume type - GSB-400. 


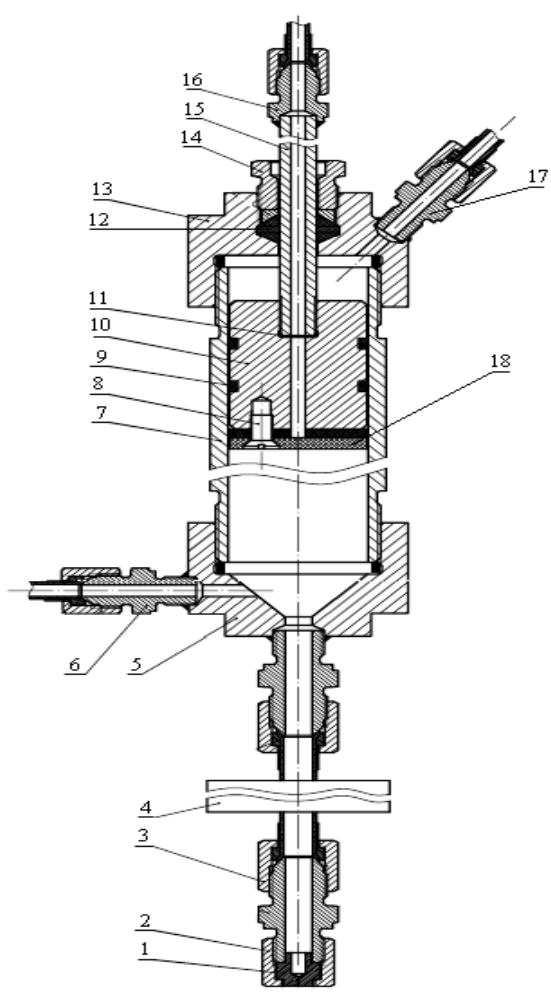

Figure 2. Powder material feeder with shutoff valve. 1-dispenser, 2 nipple, 3 - retaining unit of dispenser, 4 - shutoff valve, 5 -lower bottom of feeder, 6- nipple of lower fluidization gas supply, 7 -feeder body, 8attachment screw of gas divider filter, 9- piston seal, 10- piston, 11 attachment fitting of gas supply pipe, 12 - gas supply pipe seal, 13- top head of feeder, 14 - regulation nut of seal tightening, 15 -fluidization gas supply pipe, 16 - nipple of fluidization gas supply, 17 - nipple of gas supply for piston movement, 18 - fluidization gas divider.

Expenditure of powder gathered during the test is determined by means of weight-change method, steadiness of expenditure - by means of piston movement pick-up that's installed on the expenditure capacity of powder metal.

In process of bench operation at work process analysis mode or hydrogen synthesis analysis capacity for gas and powder gathering is detached and between combustion products purification stages heat-exchanging unit is connected, that reduces 1 st zone reaction products temperature to values that ensure working capacity of polishing filter of separator of 2nd stage. Exhaust gas is discharged to atmosphere, stability of count of the counter is recorded by means of video camera.

Powder feeder is designed for powder metal supply to the combustion chamber. It includes metal fuel expenditure capacity (Fig. 2), that consists of cylindrical body 7, calculated for operation pressure no less than $15 \mathrm{MPa}$, equipped with piston 10, lower bottom 5 and top head 13 .

Capacity is equipped with sealing valves, gas supply system for powder fluidization and orificing device 1 of fluidized powder metal to gas generator zone through shutoff valve.

Fluidization gas is supplied through the pipeline 15 , that is used for piston movement stability control as well, wherefore it is connected through slot hole to potentiometer. Gas for piston movement with pressure value from 0.5 to 1.0 MPa higher than pressure value of powder metal, that is supplied to combustion chamber, is supplied through feed line 17 to near-piston space. Pressure demand of gases is specified be means of independent reducing valves PR1-PR4 (Fig. 1). For powder expenditure reduction additional gas supply through injector nozzle to outlet conical portion of supply tank through pipeline 8 with separate reducing valve is provided. The installation is equipped with systems of pressure and temperature sensing. All the measured parameters appear to MIC-300 monitoring unit and are recorded on a real time basis. Moreover, installation operation time is identified from the moment of valve opening for powder metal supply till its closure, therefore pressure sensor is installed in work space of shutoff valve, by means of values of which launching time is calculated.

Preliminary calculation [2] illustrate that for solving many particular tasks on high-efficient installation creation expenditure of powder aluminum shall be within the range from 1 to $10 \mathrm{~g} / \mathrm{s}$. Enough developed regimes of powder supply by means of fluidization in mode of "deferred dense bed" [1], that is in case of particular calibration of supply pipeline and throttling element diameters, require for the purpose of low expenditure of mesh dimensions injector nozzle less than $5 \mathrm{~mm}$ even in case of minor compression ratio (up to $0.1 \mathrm{MPa}$ ), which causes additional complications in realization of stable powder fuel supply process.

Appearance of installation work area is shown on Fig. 3.

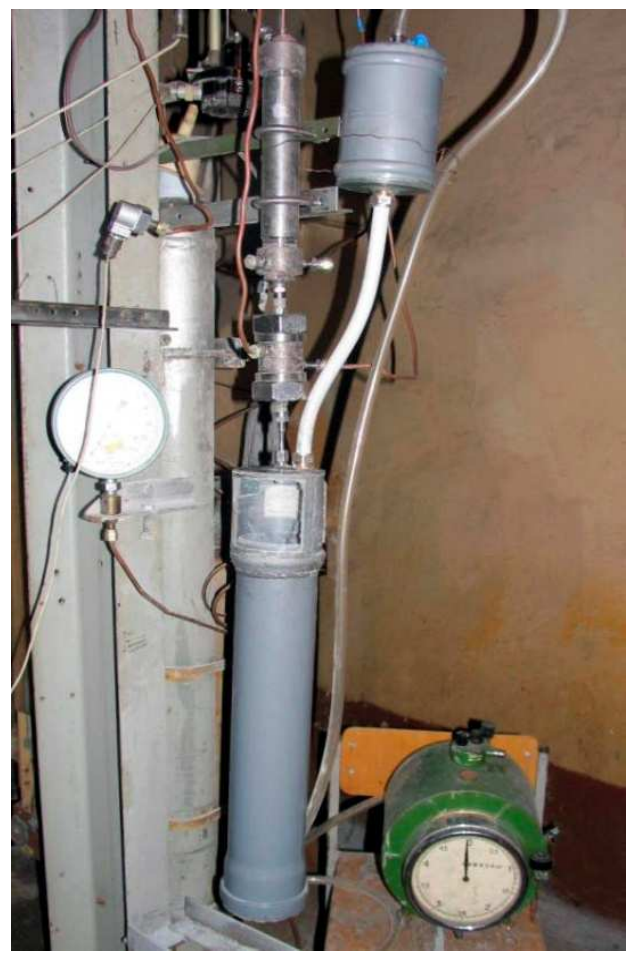

Figure 3. Appearance of installation work area in variant of powder metal fuel expenditure determination. 


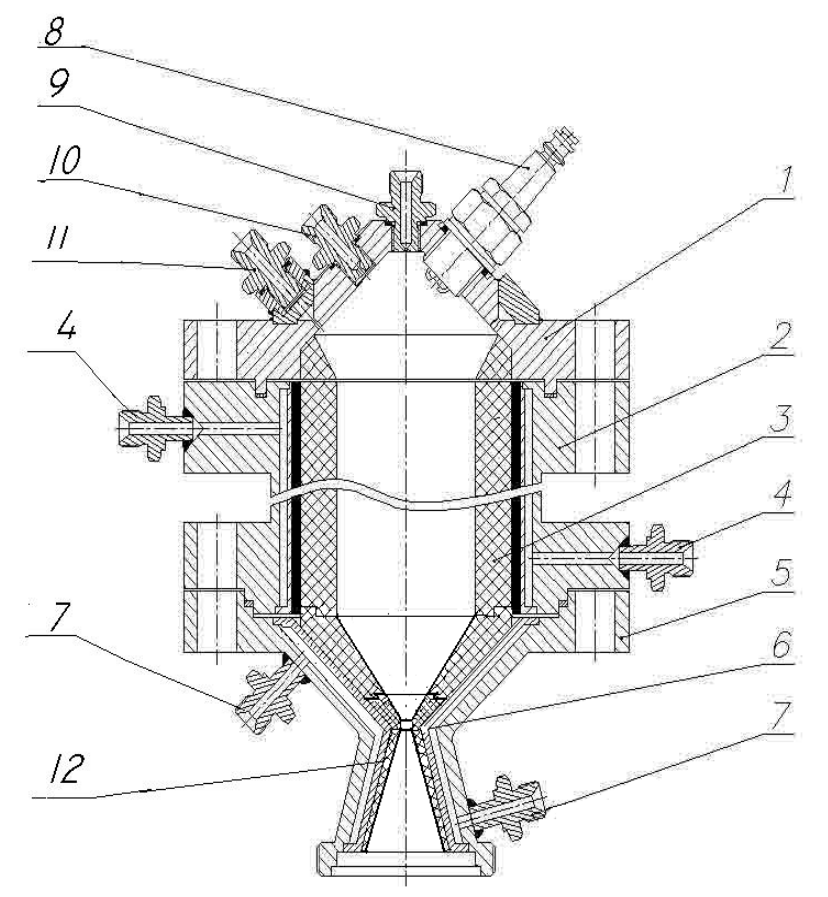

Figure 4. Generator combustion chamber.

\subsection{Research on Generator Operating Modes}

Through studies of generator operating modes combustion process is implemented in combustion chamber, that is equipped with coolant passage with independent source of coolant (water) supply from external device that allows operation with pressure value up to $3.0 \mathrm{MPa}$. Generator combustion chamber scheme is shown on the Fig. 4.

Powder fuel from the fuel (Fig. 2) through injector 9 is supplied to combustion chamber (Fig. 4). Air (water) is conducted through nipple 11 and head carrier with 8 inlets with diameter $0.5 \mathrm{~mm}$. Propellant mixture burns and comes to separator of $1 \mathrm{st}$ stage through nozzle 6 . Thermal protection of combustion chamber cylindrical section is provided by means of graphite insert; nozzle cooling is completed through self-contained cooling circuit.

Appearance of installation is shown on Fig. 5.

In combustion chamber throat changeable nozzle insert 6 is installed, throat dimensions of which for maintenance of set operating parameters are calculated depending on target pressure and fuel flow value.

For ignition of powder metal electrospark ignition system based on car igniter 8 is used. For stabilization of burning torch mode in the process of powder metal and water interaction through the nipple 10 the possibility of post feeding of combustion gas (methane, propane), that develops "following torch" of powder metal burning with air, is provided. By means of V5 isolator or EV3 valve (Fig. 1) there is possibility of auxiliary gas supply shutdown at a given time.

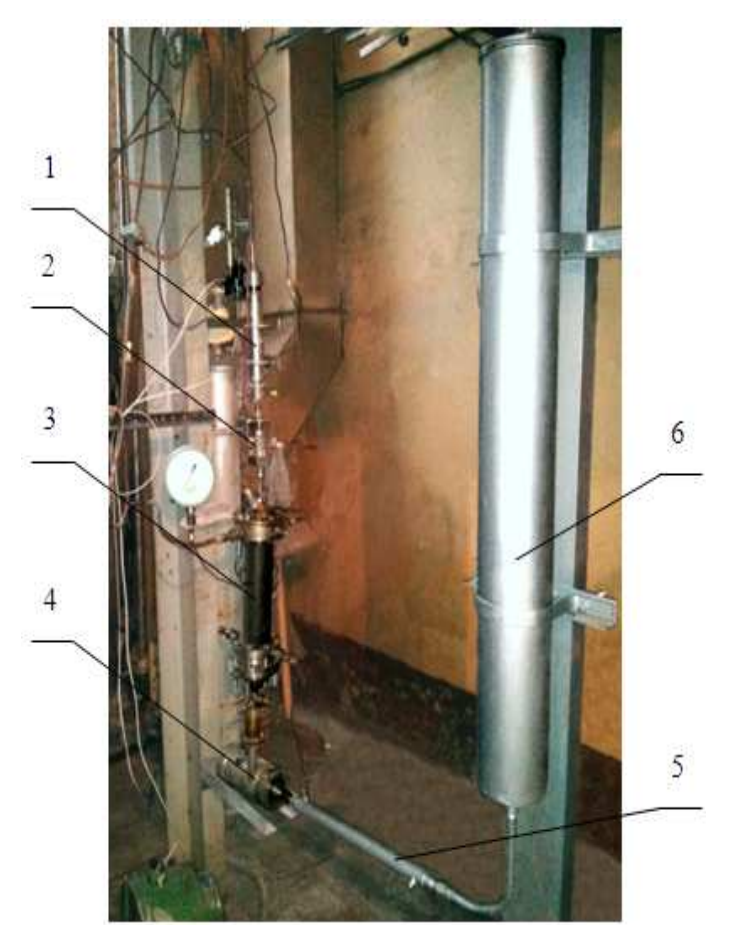

Figure 5. Appearance of installation for analysis of operating regimes of combustion chamber. 1 -feeder; 2 - powder metal valve; 3 -combustion chamber; 4 -separator; 5 - heat-exchanging unit; 6 -polishing filter.

Heat-exchanging unit that is necessary for combustion products temperature reduction before their polishing is performed on the principle of reversed flow. Coolant liquid in the heat-exchanging unit is used on independent cooling source. Its expenditure is regulated by means of V3-V4 isolators (Fig. 1). For capturing ultradispersed fractions of combustion products a polishing filter is used. It is made of capron fabric, mounted on welded frame made of non-rusting wire with diameter of $3 \mathrm{~mm}$ in separate body 6 (Fig. 5).

\section{Calculations and Results}

For operating parameters setting and analysis of internal ballistics characteristics, thermodynamics calculations in the process of aluminum and air interactions under different temperatures, pressures and components ratios $\mathrm{Km}$ were performed. Results of thermodynamics calculations of aluminum and air interaction are shown in Table 1, aluminum and water with different temperatures interactions - in Tables 2, 3 .

For combustion chamber performance support, heat flows calculation and thermal ablative protection system design combustion products temperature and relative mass concentration of condensed phase. Their dependence on mixture ratio and pressure value in combustion chamber in process of aluminum and air interaction is shown on Fig. 6, 7 and 8,9 respectively. 
Table 1. Results of thermodynamics calculations of aluminum and air interaction Properties and relative mass concentrations of key products in combustion chamber.

\begin{tabular}{|c|c|c|c|c|c|}
\hline \multicolumn{6}{|c|}{$\mathrm{pc}=1 \mathrm{MPa}$} \\
\hline $\mathrm{Km}$ & 1.0 & 2.0 & 3.0 & 4.0 & 5.0 \\
\hline $\mathrm{Tc}$ & 2875.7 & 3222.7 & 3864.2 & 3904.8 & 3710.5 \\
\hline $\mathrm{Rg}$ & 202.7 & 241.1 & 276.1 & 1293.2 & 299.4 \\
\hline $\mathrm{km}$ & 1.133 & 1.178 & 1.163 & 1.165 & 1.172 \\
\hline $\mathrm{z}$ & 0.287 & 0.210 & 0.304 & 0.322 & 0.308 \\
\hline AlN c & 0.221 & - & - & - & - \\
\hline $\mathrm{Al} 2 \mathrm{O} 3 \mathrm{c}$ & 0.065 & 0.210 & 0.304 & 0.322 & 0.308 \\
\hline $\mathrm{N} 2$ & 0.307 & 0.510 & 0.571 & 0.605 & 0.626 \\
\hline $\mathrm{A} 12 \mathrm{O}$ & 0.378 & 0.247 & 0.069 & 0.014 & - \\
\hline $\mathrm{Al}$ & 0.027 & 0.029 & 0.019 & 0.006 & - \\
\hline \multicolumn{6}{|c|}{$\mathrm{pc}=2 \mathrm{MPa}$} \\
\hline $\mathrm{Km}$ & 1.0 & 2.0 & 3.0 & 4.0 & 5 \\
\hline $\mathrm{Tc}$ & 3006.6 & 3237.6 & 3903.3 & 4021.3 & 3769.3 \\
\hline $\mathrm{Rg}$ & 203.4 & 239.6 & 270.6 & 293.1 & 298.7 \\
\hline $\mathrm{Km}$ & 1.128 & 1.178 & 1.162 & 1.162 & 1.170 \\
\hline $\mathrm{z}$ & 0.307 & 0.207 & 0.304 & 0.331 & 0.311 \\
\hline $\mathrm{N} 2$ & 0.302 & 0.510 & 0.562 & 0.605 & 0.624 \\
\hline $\mathrm{Al} 2 \mathrm{O}$ & 0.364 & 0.255 & 0.093 & 0.012 & 0.002 \\
\hline $\mathrm{Al}$ & 0.025 & 0.025 & 0.019 & 0.004 & 0.001 \\
\hline AlN c & 0.235 & - & - & - & - \\
\hline $\mathrm{Al} 2 \mathrm{O} 3 \mathrm{c}$ & 0.072 & 0.207 & 0.304 & 0.331 & 0.311 \\
\hline \multicolumn{6}{|c|}{$\mathrm{pc}=3 \mathrm{MPa}$} \\
\hline $\mathrm{Km}$ & 1.0 & 2.0 & 3.0 & 4.0 & 5 \\
\hline $\mathrm{Tc}$ & 3089.3 & 3244.8 & 4018.7 & 4097.9 & 3797.6 \\
\hline $\mathrm{Rg}$ & 203.9 & 238.9 & 275.8 & 292.5 & 298.3 \\
\hline $\mathrm{Km}$ & 1.125 & 1.178 & 1.160 & 1.159 & 1.169 \\
\hline $\mathrm{z}$ & 0.320 & 0.206 & 0.314 & 0.336 & 0.312 \\
\hline $\mathrm{Al} 2 \mathrm{O} 3 \mathrm{c}$ & 0.076 & 0.206 & 0.314 & 0.336 & 0.312 \\
\hline $\mathrm{N} 2$ & 0.299 & 0.510 & 0.572 & 0.602 & 0.624 \\
\hline $\mathrm{Al} 2 \mathrm{O}$ & 0.355 & 0.259 & 0.071 & 0.013 & 0.002 \\
\hline $\mathrm{Al}$ & 0.025 & 0.023 & 0.015 & 0.005 & 0.001 \\
\hline $\mathrm{AlN} \mathrm{c}$ & 0.243 & - & - & - & - \\
\hline
\end{tabular}

Note. Index «c» in tables means that the material is in condensed phase. Tc, $\mathrm{Rg}, \mathrm{km}$ - temperature, gas constant, adiabatic exponent of gas combustion products; $\mathrm{z}$ - relative mass concentration of condensed combustion products.

Table 2. Results of thermodynamics calculations of aluminum and water interaction. Water supply temperature is $20^{\circ} \mathrm{C}$. Properties and relative mass concentrations of key products in combustion chamber.

\begin{tabular}{|c|c|c|c|c|c|}
\hline \multicolumn{6}{|c|}{$\mathrm{pc}=1 \mathrm{MPa}$} \\
\hline $\mathrm{Km}$ & 1.0 & 2.0 & 3.0 & 4.0 & 5.0 \\
\hline $\mathrm{Tc}$ & 3025.7 & 2237.7 & 1526.8 & 1081.1 & 768.6 \\
\hline $\mathrm{Rg}$ & 2831.3 & 831.9 & 656.0 & 593.5 & 561.4 \\
\hline $\mathrm{km}$ & 1.105 & 1.139 & 1.170 & 1.198 & 1.224 \\
\hline $\mathrm{z}$ & 0.915 & 0.630 & 0.472 & 0.378 & 0.315 \\
\hline $\mathrm{Al} 2 \mathrm{O} 3 \mathrm{c}$ & 0.915 & 0.630 & 0.472 & 0.378 & 0.315 \\
\hline $\mathrm{H} 2$ & 0.053 & 0.037 & 0.028 & 0.022 & 0.019 \\
\hline $\mathrm{H} 2 \mathrm{O}$ & 0.009 & 0.333 & 0.500 & 0.600 & 0.666 \\
\hline $\mathrm{A} 12 \mathrm{O}$ & 0.012 & - & - & - & - \\
\hline \multicolumn{6}{|c|}{$\mathrm{pc}=2 \mathrm{MPa}$} \\
\hline $\mathrm{Km}$ & 1.0 & 2.0 & 3.0 & 4.0 & 5.0 \\
\hline $\mathrm{Tc}$ & 3064.1 & 2239.0 & 1527.2 & 1082.4 & 772.1 \\
\hline $\mathrm{Rg}$ & 2899.3 & 831.7 & 656.0 & 593.5 & 561.4 \\
\hline $\mathrm{km}$ & 1.104 & 1.139 & 1.117 & 1.198 & 1.221 \\
\hline $\mathrm{z}$ & 0.918 & 0.630 & 0.472 & 0.378 & 0.315 \\
\hline
\end{tabular}



Installation for Analysis of Work Process in Hydrogen Synthesis Power Systems on Powder Aluminium

\begin{tabular}{cccccc}
\hline $\mathrm{Al} 2 \mathrm{O} 3 \mathrm{c}$ & 0.918 & 0.630 & 0.472 & 0.378 & 0.315 \\
$\mathrm{H} 2$ & 0.054 & 0.037 & 0.028 & 0.022 & 0.019 \\
$\mathrm{H} 2 \mathrm{O}$ & 0.009 & 0.333 & 0.500 & 0.600 & 0.666 \\
$\mathrm{Al} 2 \mathrm{O}$ & 0.011 & - & - & - & - \\
& & $\mathrm{pc}=3 \mathrm{MPa}$ & 4.0 & 5.0 \\
$\mathrm{Km}$ & 1.0 & 2.0 & 3.0 & 1083.5 & 775.5 \\
$\mathrm{Tc}$ & 3084.5 & 2240.4 & 1527.5 & 593.5 & 561.4 \\
$\mathrm{Rg}$ & 2945.6 & 831.6 & 656.0 & 1.197 & 1.217 \\
$\mathrm{~km}$ & 1.104 & 1.139 & 1.170 & 0.378 & 0.315 \\
$\mathrm{z}$ & 0.919 & 0.630 & 0.472 & 0.378 & 0.315 \\
$\mathrm{Al} 2 \mathrm{O} 3 \mathrm{c}$ & 0.919 & 0.630 & 0.472 & 0.022 & 0.019 \\
$\mathrm{H} 2$ & 0.054 & 0.037 & 0.028 & 0.600 & - \\
$\mathrm{H} 2 \mathrm{O}$ & 0.008 & 0.333 & 0.500 & - & - \\
$\mathrm{Al2O}$ & 0.012 & - & - & - & - \\
\hline
\end{tabular}

Table 3. Results of thermodynamics calculations of aluminum and heated up to 1500 water interaction Properties and relative mass concentrations of key products in combustion chamber.

\begin{tabular}{cccc}
\hline & & $\mathrm{pc}=1 \mathrm{MPa}$ & \\
\hline $\mathrm{Km}$ & 1.0 & 2.0 & 3.0 \\
$\mathrm{Tc}$ & 3092.3 & 2310.8 & 1722.0 \\
$\mathrm{Rg}$ & 2621.2 & 831.8 & 656.0 \\
$\mathrm{~km}$ & 1.106 & 1.134 & 1.164 \\
$\mathrm{z}$ & 0.908 & 0.609 & 0.472 \\
$\mathrm{Al2O} 3 \mathrm{c}$ & 0.908 & 0.609 & 0.472 \\
$\mathrm{H} 2$ & 0.053 & 0.036 & 0.028 \\
$\mathrm{H} 2 \mathrm{O}$ & 0.014 & 0.354 & 0.500 \\
$\mathrm{~A} 12 \mathrm{O}$ & 0.014 & - & - \\
$\mathrm{Km}$ & & & 3.0 \\
$\mathrm{Tc}$ & 1.0 & 2.0 & 1722.5 \\
$\mathrm{Rg}$ & 3160.4 & $\mathrm{MPa}$ & 656.0 \\
$\mathrm{~km}$ & 2725.7 & 2314.6 & 1.163 \\
$\mathrm{z}$ & 1.104 & 831.8 & 0.472 \\
$\mathrm{Al2O} 3 \mathrm{c}$ & 0.912 & 1.210 & 0.472 \\
$\mathrm{H} 2$ & 0.912 & 0.609 & 0.028 \\
$\mathrm{H} 2 \mathrm{O}$ & 0.053 & 0.609 & -
\end{tabular}

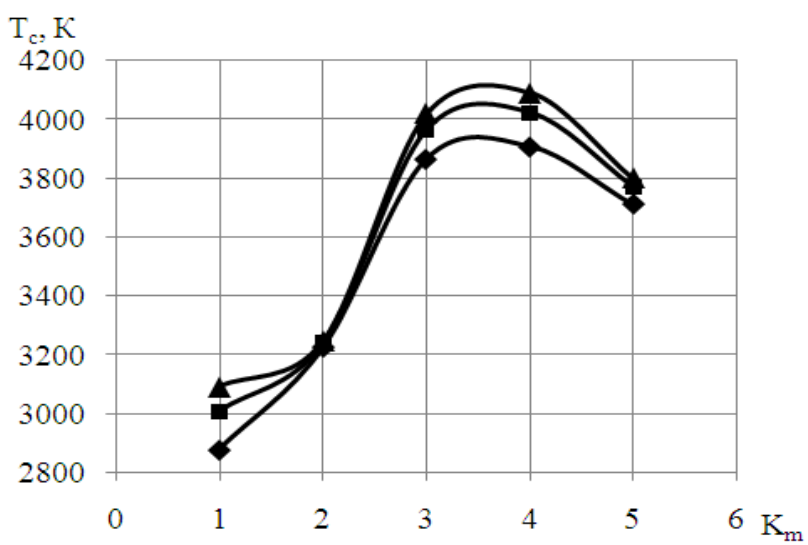

Figure 6. Dependence of combustion products temperature on components ratio (aluminum-air).Pressure in the combustion chamber: $\checkmark-1 \mathrm{MPa} ; \boldsymbol{\square}-2 \mathrm{MPa} ; \boldsymbol{\Lambda}-3 \mathrm{MPa}$

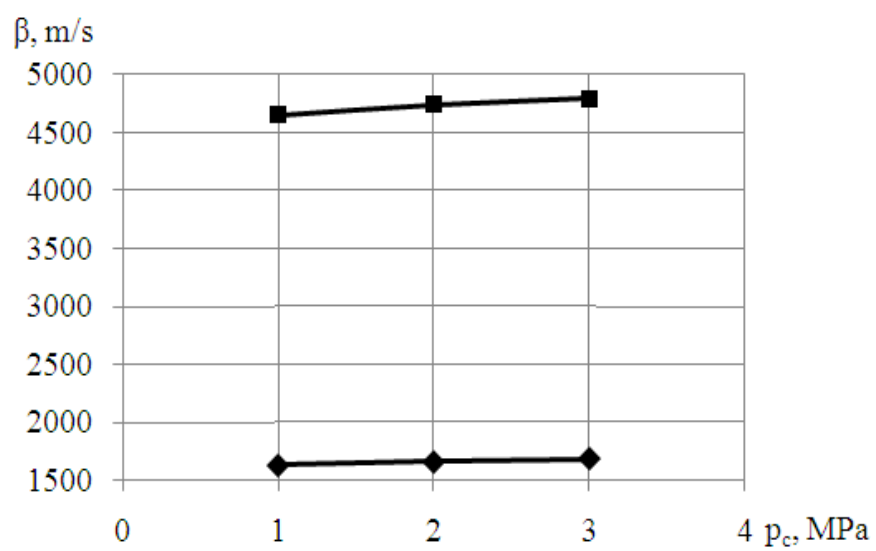

Figure 7. Dependence of relative mass concentration of condensed phase on components ratio (aluminum-air). Pressure in the combustion chamber: -1 $\mathrm{MPa} ; \mathbf{\square}-2 \mathrm{MPa} ; \mathbf{\Delta}-3 \mathrm{MPa}$ 


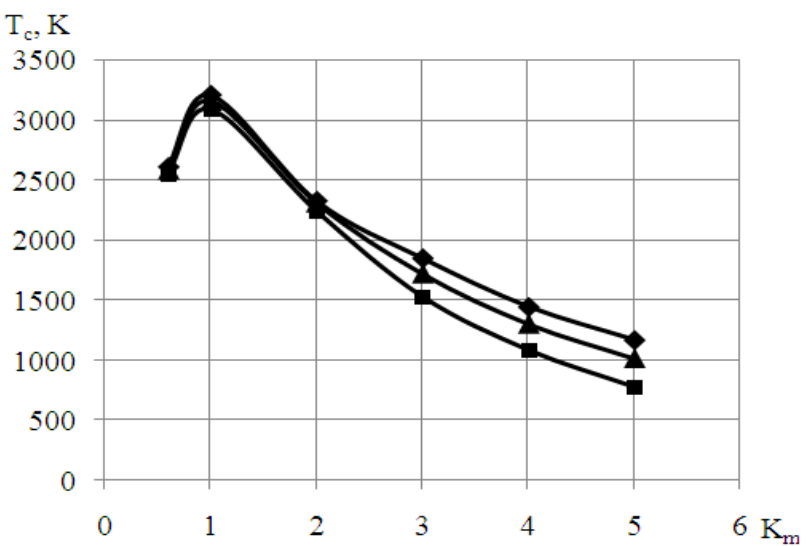

Figure 8. Dependence of combustion products temperature on components ratio. Water temperature $\left(p_{c}=3 \mathrm{MPa}\right):-250^{\circ} \mathrm{C} ; \boldsymbol{\Delta}$ $150{ }^{\circ} \mathrm{C} ; \mathbf{\square}-20^{\circ} \mathrm{C}$

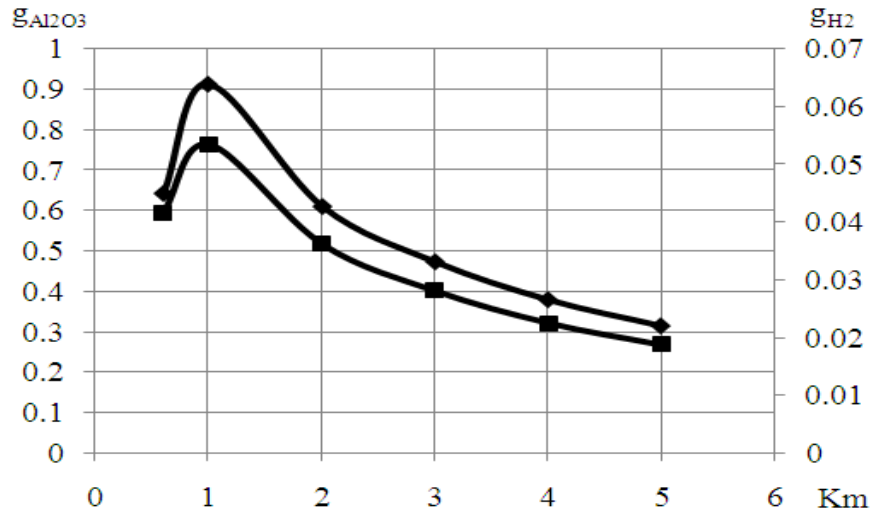

Figure 9. Dependence of relative mass concentration of aluminum oxide and hydrogen on ratio (aluminum-water $150^{\circ} \mathrm{C}, p c=3 \mathrm{MPa}$ ). Substances: aluminum oxide; - $\mathbf{-}$-hdrogen

Table 4. Nozzle throat size under condition of different fuel consumption values for components close to stoichiometric relationships

\begin{tabular}{|c|c|c|c|c|c|c|c|c|c|c|}
\hline $\mathrm{pc}, \mathrm{MPa}$ & & 1 & & & 2 & & & 3 & & \multirow{3}{*}{$\begin{array}{l}\text { Mixture ratio } \\
\mathrm{Km}\end{array}$} \\
\hline $\mathrm{mf}, \mathrm{g} / \mathrm{s}$ & 1 & 10 & 100 & 1 & 10 & 100 & 1 & 10 & 100 & \\
\hline \multicolumn{10}{|c|}{ Nozzle throat diameter, $\mathrm{mm}$} & \\
\hline Reaction with air & 3.1 & 9.8 & 30.8 & 2.2 & 6.9 & 21.8 & 1.8 & 5.6 & 17.8 & 3.5 \\
\hline $\begin{array}{l}\text { Reaction with water } \\
\qquad\left(20^{\circ} \mathrm{C}\right)\end{array}$ & 3.5 & 11.0 & 34.7 & 2.5 & 7.8 & 24.5 & 2.0 & 6.3 & 20.0 & 1 \\
\hline
\end{tabular}

Specification of diameter of nozzle throat (assuming of loss free conditions in the installation chamber) was made by the equation

$$
d_{c r}=\left[4 \cdot \beta \cdot m_{f} \cdot\left(1+K_{m}\right) /\left(p_{c} \cdot \pi\right)\right]^{0.5}
$$

where $\mathrm{m}_{\mathrm{f}}$ - powder metal mass flow through combustion chamber, $\beta=\left(p_{c} \cdot f_{c r}\right) / m_{\Sigma}-$ flow rate complex with equilibrium values as shown on Fig. 10.

In the Table 4 nozzle throat size under condition of different fuel consumption values for components close to stoichiometric relationships is shown. In the calculation process combustion efficiency was taken to be equal to 1 .

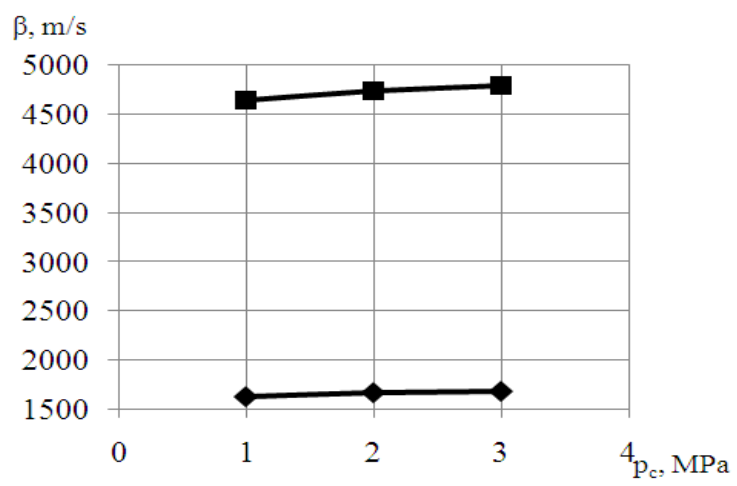

Figure 10. Dependency of flow rate complex on combustion chamber pressure. - interaction with air; $\boldsymbol{\square}$-with water

In process of bench optimization preliminary tests were undertaken, which were supposed to determine expenditure of powder aluminum ASD-4 and lift gas under different values of pressure ration on piston and injector unit.

On Fig. 11 dependency of powder metal flow on differential pressure on kicking coil with diameter of 0.5 and $1 \mathrm{~mm}$ is shown. Registered dependencies affirm that as well as in case of water supply mass flow is proportional to differential pressure $\Delta p d r$ raised to the power of $\sim 1 / 2$.

It's specified that in pressure range of lifting gas up to $1 \mathrm{MPa}$ relative mass fraction of gas (air) in case of kicking coil diameter of $0.75 \mathrm{~mm}$ is no higher than $6-7 \%$ of powder metal flow. In a process of further installation optimization above mentioned value of flow demand can be optimized.

Typical appearance of oscillogram of key parameters record collected in package of WinPOS reprocessing is shown on Fig. 12.

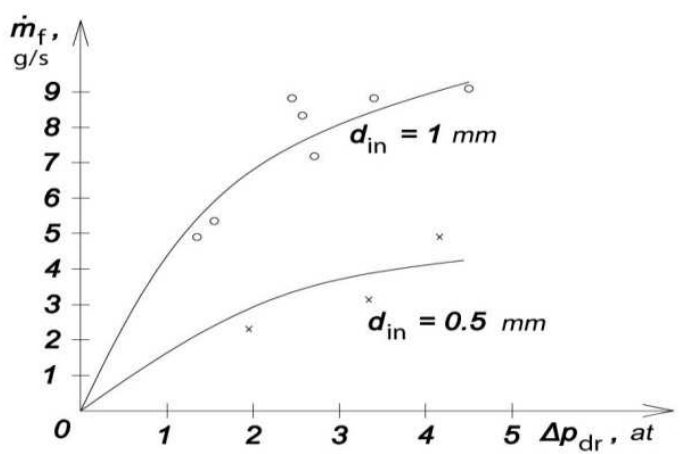

Figure 11. Dependency of ASD-4 powder metal fuel flow on differential pressure on atomized-spray injector and injector diameter. 


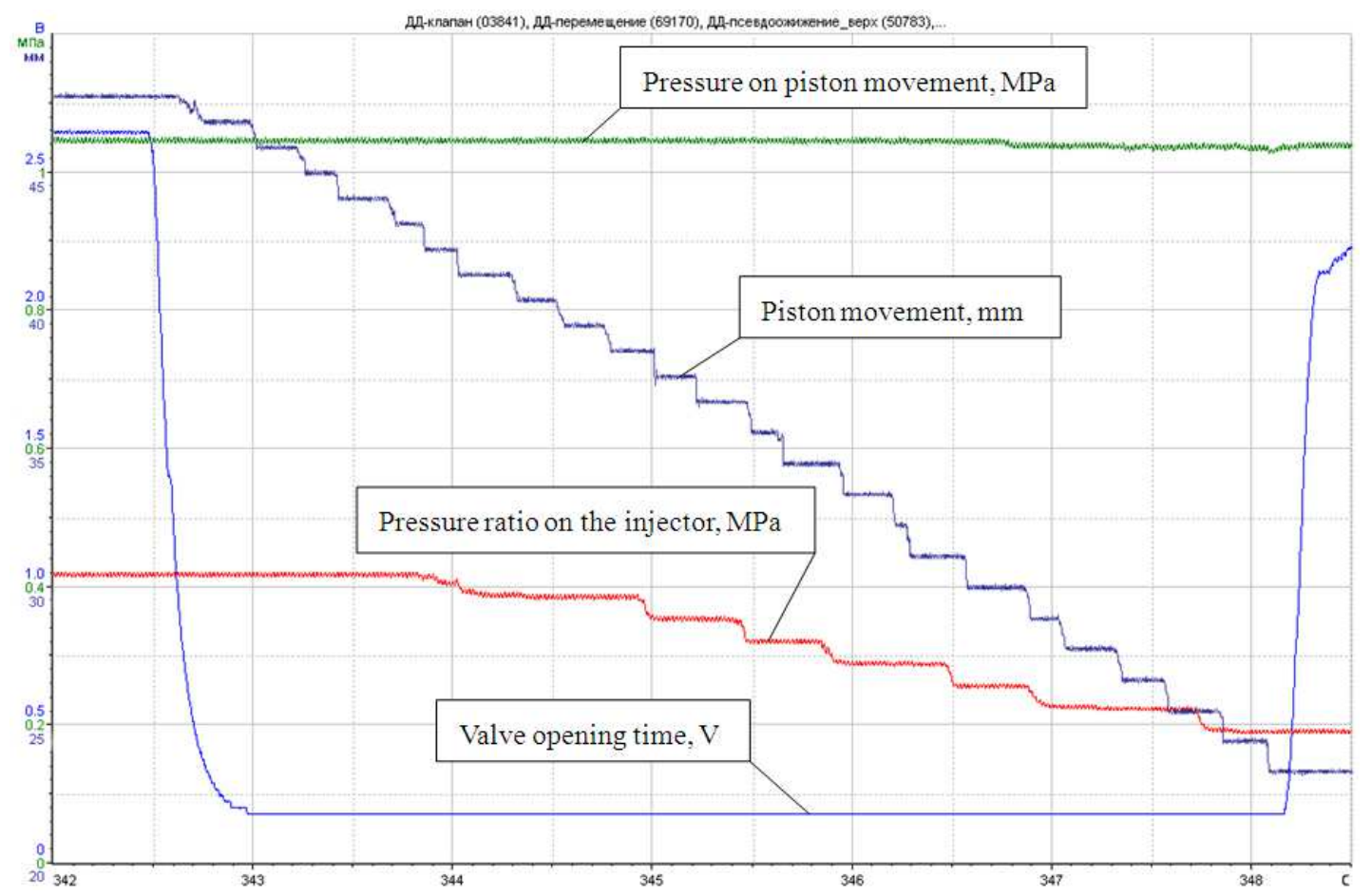

Figure 12. Typical appearance of oscillogram of key parameters record

\section{Conclusion}

Therefore, presented installation allows experimentally optimize parameters of expulsion system of metal powders, which includes aluminum powder, of such marks as ASD, PAP, PAD to combustion chamber, choose optimal lift gas for fluidization and supply of powder metal, calibrate powder metal gas suspension expenditure measurement fitting by means of specifically developed system of powder expenditure determination and minimize lift gas expenditure in the process of powder metal supply of fixed flow rate. During preliminary experiment series powder metal system performance based on ASD-4 aluminum in case of flow of the latter up to $15 \mathrm{~g} / \mathrm{s}$ and relative mass fraction of lifting air no more than $6 \%$ was confirmed.

\section{References}

[1] O. E. Shatskiy, A. A. Shcherbakov, Yu. N. Vlasov, "Fluidized Powders Supply in Mode of Stagnation Dense Layer," Combustion Processes and Environmental Conservation, RATI, Rybinsk, 1993, pp. 43-47.

[2] B. G. Trusov, "Program system TERRA for simulation phase and thermal chemical equilibrium," Proceedings of the XIV International Conference on Chemical Thermodynamics, St-Petersburg, Russia, 2002, pp. 483-484.

[3] D. A. Yagodnikov, "Powder Metals Ignition and Combustion," MSTU named after N. E. Bauman publ., Moscow, 2009, p. 432. 